\title{
Changing systems of external monitoring of quality of health care in the United States
}

In the preceding article ( $p$ 97) I described the origins and current structure and functions of the principal systems of external quality monitoring in the United States. As institutions operating in a complex and sometimes contentious area, these organisations have been subject to several pressures for change. This paper examines five of these pressures (box), among which perhaps the most important potential influence is the question of national health care reform.

\section{Balancing internal and external quality improvement initiatives}

The concept of continuous quality improvement in health care originates from industrial quality improvement programmes ${ }^{2-5}$ and emphasises the systematic origin of quality problems. It seeks to improve quality by improving overall performance rather than by detecting "unacceptable care." ${ }^{\prime 6}$ Historically, the external inspection methods of peer review as practised by the Peer Review Organisations have been at odds with this philosophy and have created tension between proponents of continuous quality improvement and external quality improvement. Although criticisms of the external inspection model have been productive in that changes in the Peer Review Organisation programme have resulted, the strength of criticism has created an apparent incompatibility between continuous quality improvement and all forms of external quality improvement. ${ }^{7}$ The critical task for those charged with designing systems for monitoring quality is not only to find a way of making these two models compatible ${ }^{8}$ but mutually supportive. ${ }^{9-13}$ A global system of quality improvement based solely on internal quality improvement presents insurmountable problems as it would be devoid of a system of public protection and external accountability. Conversely, an entirely external system would be equally insupportable because it would have to rely entirely on inspection, generating a cycle of fear and antagonism, and would not create an environment likely to support improvement. There are as yet no examples of systems that have perfected this mix, although some developments such as the Maryland Hospital Association's quality improvement project suggested that the direction of change is towards integration.

Role of corporate health care purchasers The increased role of corporate purchasers in attempting to influence health care policy largely stems from a recognition of the effect of spiralling health care costs on the

\section{Pressures for change among organisations providing external quality monitoring of health care in the United States \\ - Balance between internal and external quality improvement \\ - Increasing role of consumers in measuring and improving quality \\ - Increased prominence of large corporate purchasers \\ - Criticism of existing systems \\ - National reform of health care}

global competitiveness of North American business. ${ }^{14-16}$ However, various coalitions of large corporations have also been prominent in considering how best to monitor the quality of the care that is purchased on behalf of their employees. In constructing their agreements with managed care organisations, many corporate purchasers have used the expertise of their internal benefits departments or have contracted with external specialists to determine the quality of care offered by competing plans. The details of such analyses are not usually made available to employees, who are often offered a fait-accompli in terms of the available plans and the weightings that are applied to the employees' contributions to them. If this trend towards corporations organising their own quality assessments were to continue, the overall result would be an increase in the complexity and fragmentation of the system of external review, with a multitude of under-resourced small organisations. The public support given by business coalitions to the National Committee for Quality Assurance, the major quality monitor for the managed care industry, is an attempt to standardise the processes by which quality is monitored and therefore to use the resources allocated to quality monitoring more cost effectively. It may also be seen as an attempt to pre-empt government action on standardising quality improvement mechanisms, as the National Committee for Quality Assurance is an independent organisation. Business coalitions have been prominent in the attempts to get Health Maintenance Organisations to become accredited by the committee and to agree to public presentation of report cards outlining their performance. ${ }^{17} 18$ The recently announced Health Plan Employer Data and Information Set (HEDIS) is a collection of performance measures designed by the committee in collaboration with other groups to meet the needs of 
employers to measure and compare the performance of different health care plans. ${ }^{19}$

The notion of performance in HEDIS is divided into five main areas: quality, access and patient satisfaction, membership and utilisation, finance, and descriptive information of the management of the health plan. The quality measures that have been chosen are relatively simple and fall into four groups: preventive services (childhood immunisation and screening for cholesterol concentration and breast and cervical cancers); prenatal care (the frequency of low birth weight and the occurrence of prenatal care in the first trimester); acute and chronic illnesses (the asthma inpatient admission rate and the frequency of retinal examination in patients with diabetes); and mental health (the frequency of ambulatory follow up after hospitalisation for major affective disorders). Although the report specifies the exact way in which these quality measures are to be calculated, there is still scope for plans to present their data differently. As many major employers are expected to compare plans using these measures, it is not surprising that some plans have decided to achieve a competitive advantage by publicising their results. The need for external validation of these claims of excellence has been demonstrated by the publication of some results in which it is unclear whether the measures refer to the average performance of the plan as a whole or are a list of the plan's best performance in each of the categories in any of its centres.

\section{Role of consumers and consumer organisations}

Direct consumers of health care have an important role in providing information about the quality of care by responding to satisfaction surveys and measuring technical quality by the use of patient focused outcome variables. $^{20-22}$ However, perhaps the more contentious issue is the role of the consumer as user of information about technical quality. The protagonists in the debate about public availability of information on the quality of care are not only involved in an argument about the public's right to this knowledge nor the feasibility of providing it in a comprehensible fashion. Rather this debate is intimately related to the question of whether or not the solution to the demonstrable failure of the health care market and the general ills of the United States health care system is through pro-competitive reform. Market enthusiasts regard the public release of these data as an important step which will reenfranchise the consumer of health care, provide purchasers of health care with an improved basis on which to base their purchasing decision, and expedite progress in the development of additional measures that can facilitate comparative evaluations of physicians by consumers. Examples of how various organisations have attempted to "re-enfranchise the consumer" are relatively easy to find.
The public release of Health Care Financing Administration Medicare mortality data $^{23}$ has generated considerable controversy, most notably about their validity and reliability. ${ }^{24-26}$ Although consumer organisations like the Washington Center for the Study of Services ${ }^{27}$ have tried to make the information more accessible by reducing the statistics to a single volume (from 25 volumes), there is no evidence to suggest that this move has helped individuals to make more informed choices about the hospitals they should attend. The complexity of the data and the difficulty of making statistical inferences from rates based on small numbers suggest

\section{Although there is no information on how [mortality] data are used by consumers, it would be difficult to argue that they should not be publicly available.}

that this is unlikely. Although there is no information on how such data are used by consumers, it would be difficult to argue that they should not be publicly available. Indeed in a celebrated case brought by a news reporter against New York state, the State Supreme Court ruled that comparative information on operative mortality rates for coronary artery bypass grafting held by the State Department of Health could be made publicly available, against the wishes of the state. If the publication of institution specific mortality data is complex, the publication of physician-specific operative mortality rates is highly contentious. The Pennsylvania Health Care Cost Containment Council, an independent state agency responsible for addressing the cost and quality of health care, has produced risk-adjusted mortality rates for the surgeons operating within the state. ${ }^{28} 29$ The inferences that can be drawn from the data are limited by the numbers of cases involved and therefore by the statistical strength of the data. This is especially true of those clinicians who operate on a limited number of cases. The council acknowledges this by excluding those physicians who operate on fewer than 30 patients a year. If the general relation between volume and quality ${ }^{30}$ holds in this instance, then this creates an immediate paradox whereby those at greatest risk of providing poor quality care are excluded from the analysis.

The impact on the external monitoring organisations of the increasing moves to make information about the quality of care publicly available remains uncertain. It may be that their importance is not in "re-enfranchising the consumer" as the pro-competitive reformers would have it, not only for reasons of feasibility ${ }^{31}$ but also because there is evidence to suggest that even without such data individual decisions are qualitysensitive. ${ }^{32}$ Rather these trends may contribute 
in a more general way to an increased awareness among health care providers of the need to be publicly accountable for their results.

\section{Criticism of existing systems}

As the preceding article ${ }^{1}$ suggested, the Peer Review Organisation programme (established to monitor the quality of care given to Medicare patients) has been subject to considerable criticism. As a result the Institute of Medicine, a branch of the National Academy of Sciences, was asked by Congress to undertake an extensive review of the whole Medicare quality assurance programme and to devise a new strategy if necessary. Its report suggested the establishment of a national council of experts who could oversee the operations of the Peer Review Organisation programme and report periodically to the Secretary of the Department of Health and Human Services or to the Congress. ${ }^{33}$ The committee decided against the recommendation of an entirely new infrastructure, suggesting instead that Congress should restructure the Peer Review Organisation programme, changing its name to the Medicare Program to Assure Quality and that of the Peer Review Organisations to Medicare quality review organisations.

The recommendations of the Institute of Medicine have not been implemented, although in response to these and other criticisms, the Health Care Financing Administration announced a major change in direction for the Peer Review Organisation programme entitled the Health Care Quality Improvement Initiative. The principal component of this was a reduced emphasis on dealing with individual clinical concerns and increased attention on helping physicians and providers improve mainstream care. ${ }^{34} 35$ Central to this vision was the construction of a database (a uniform clinical data set) in which processes of care could be linked to outcomes, thus shifting the "focus away from performing case by case reviews towards a broader-based epidemiologic analysis of the health care purchased by the Medicare program." ${ }^{34}$ The practical realities of this vision have since become apparent, and the emphasis within the Medicare programme has moved from trying to collect large sets of data to directly measure quality to the construction of smaller data sets that can be used to indicate and monitor quality. The previous quality improvement mechanisms within the Medicare programme have largely ignored ambulatory care, and in the light of the more general shift within the United States health care system towards managed care, the Health Care Financing Administration has started to place greater emphasis on developing quality measurement instruments that are of use in primary care. ${ }^{36}$

The Joint Commission on the Accreditation of Healthcare Organisations has also been attempting to address its critics by reacting to the suggestion that it has historically focused only on the structural and process-oriented elements of quality. In 1986 it launched an "agenda for change" 37 whose basis was three initiatives. Among these, the survey and accreditation initiative is centred on improving the ways in which the commission assesses organisational and clinical quality by developing indicators of performance, refining risk-adjustment methods, and establishing an ongoing monitoring and evaluation process. The work on clinical indicators had led to the publication of a guidebook on the development and application of clinical indicators. $^{38} 39$ The second and third major initiatives are in education and external communication, designed to improve the interactions of the commission with health care providers.

The commission is hampered by several organisational features which may reduce the effectiveness of its change in direction. Most notably its assessments by teams of inspectors are periodic rather than continuous, and there is considerable organisational distance between the sites being visited and the commission's headquarters. Also the amount of information linking processes with outcomes is limited. Thus, although the move towards greater utilisation of outcomes in the measurement of quality is in keeping with more general trends, the nature of accreditation is such that an extended role for the commission is unlikely.

\section{Health care reform}

The public debate about health care reform in the United States both before and after President Clinton's election has focused on the twin issues of cost containment and universal access to health care. A wide variety of financing and organisational systems that might be introduced to address these problems has been considered, but, by contrast, relatively little public attention has been given to quality of care. One explanation could be that hitherto most of the public, the

\begin{tabular}{c}
\hline \hline .. most of the public, the \\
medical profession, and the \\
policymakers believed that \\
overall medical care costs could \\
be reduced without affecting \\
quality.
\end{tabular}

medical profession, and the policy makers believed that overall medical care costs could be reduced without affecting quality. ${ }^{40}$ Within interested groups, however, the possibility of major reform of the health care system has led to speculation about not only how that might affect existing quality monitoring systems but also whether the opportunity exists for more radical restructuring. In particular, the question has been raised whether the multiple overlapping and competing systems could be simplified $^{10}$ so that a single organisation had responsibility for monitoring the quality of 
care given to a particular population. Such an idea has arisen before; indeed, in 1975 Brook et al speculated that "with the coming of national health insurance, the Professional Standards Review Organisation programme will likely expand to review the care provided to the entire population." ${ }^{41}$ Although such speculation was premature as universal coverage did not arrive, it raised the important question of whether "area-wide review work(s) better than ... review which is coextensive with the agency providing the care." 41 The problems that external quality monitoring organisations have historically faced and the various policy pressures that have been described would suggest that such a restructuring may be timely.

Although the Clinton plan has met with widespread approval, the political process of moving from legislation into real change will necessitate many compromises, and the eventual shape of the system may be very different from that proposed in the act. The basic structure of the reforms is for each state to have several health alliances which would be run by the states with federal supervision. A health alliance is a purchasing group buying health care services for thousands of consumers. It is proposed that these organisations will be of two types: regional alliances established by the states and corporate alliances which in general may be set up by employers with more than 5000 employees. Their responsibility would be to collect and distribute premiums, certify health plans, and offer them to consumers. They would be required to ensure that premiums rose no faster than a federally set limit, and they would publish data on the performance of health plans. A range of health plans would be offered by the alliances but would have to include at least one fee for service option which would offer unlimited choice. The cheapest option for consumers would most likely be a managed care plan in which care could be provided only by physicians affiliated to that organisation.

Each year the health alliances will be required to publish a performance report for each of the health plans that they offer, using an established set of national quality measures. These measures will be selected by the council of the National Quality Management Programme, a group of 15 individuals representing the interests of governmental and corporate purchasers, the health plans, the states, health care providers, and the research establishment. The proposed Health Security Act $1993^{41 a}$ is specific about the criteria that the council is to use in drawing up its list. Measures will be developed only for conditions that are significant in terms of prevalence, morbidity, mortality, or cost. The set of measures will have to reflect the range of services that are provided and be of proven reliability and validity. The collection of the data required to calculate the measure will not be allowed to create an undue burden on the organisation or individual providing the information. A criterion is included requiring that measures will be constructed only where sufficient variation exists between individuals and health care providers. The authors of the act have taken on the importance of outcomes of care by requiring that where a chosen measure is a process there must be a clearly established link between that process and a health outcome. Finally if the proposed measure is an outcome of care, the causal mechanisms that lead to that outcome must be within the control of the provider (with risk adjustment were necessary) for it to be included as one of the approved quality measures.

In addition to these measures of quality, the National Quality Management Council will be asked to conduct consumer surveys to gather information about access to care, the use of health services, health outcomes, and patient satisfaction. The sampling techniques of these surveys will be designed to ensure that vulnerable populations at risk of receiving inadequate care are included.

Although the Clinton reform proposals are principally designed to tackle the central issues of universal access to health care and

\section{... the Clinton reform proposals ... have also presented an opportunity to review how information about quality is collected and disseminated.}

escalating costs, they have also presented an opportunity to review how information about quality is collected and disseminated. The criteria that have been laid out to help the council in selecting its list of quality measures should ensure valid comparisons between health plans on the basis of published information. Indeed, the criteria may be sufficiently strict to limit the list to only a handful of measures. The major step in the act is the creation of a centralised system capable of describing the quality of care at a population level, in marked distinction to the current system of fragmentary institution based assessment. Whether the alliances will simply collate the information provided for them by health plans or will require some form of independent assessment remains uncertain, although the act seems to suggest the former. Given the extent to which states are to be given autonomy in deciding the details of their health care systems, the quality monitoring systems will probably also differ quite substantially between states.

If an independent organisation were required to collect information on behalf of the alliances, there would be several possible contenders for this role. The Peer Review Organisations believe that they have an infrastructure that could be adapted to an extended role particularly as they are already state based, in contrast to the centralised Joint Commission on Accreditation of Healthcare 
Organisations and National Committee for Quality Assurance. ${ }^{42}+3$ However, under such circumstances the success of the Peer Review Organisations would be highly dependent on their ability to establish relations with both providers and purchasers of care based on trust. The current changes under the Health Care Financing Administration's Health Care Quality Improvement Initiative present an opportunity to demonstrate that such trust is not misplaced.

\section{Conclusions}

The current systems of external quality monitoring in the United States are a confused mix of private and public systems, with the principal objectives being split between public protection, quality improvement, and cost containment. These historical roles have been challenged by the increased focus on providing information to consumers and corporate purchasers of care. The debate about health care reform has provided an opportunity to consider the wholesale redevelopment of the system, but the final structure and function of a redesigned system will depend upon which of these objectives is deemed to be most important.

In presenting his proposals to a combined meeting of Congress, President Clinton stated that if "we reformed everything else in health care but failed to preserve and enhance the high quality of our medical care, we will have taken a step backward, not forward." +4 Whether the quality monitoring system that is proposed in the act "can serve the highest ideals of medical professionalism and ease the potential for destructive confrontation between the economic and medical models of health care" $\$ 5$ remains to be seen.

I am particularly indebted to Dr Heather Palmer, Director of the Center for Quality of Research and Education, and to the Commonwealth Fund of New York, the organisers of th Harkness Fellowship programme, for their support. An opinions expressed are mine and do not reflect the views of the centre or the fund.

1 Wareham NJ. External monitoring of quality of health care in the United States. Quality in Health Car 1994;3:97-101.

2 Berwick DM. Continuous improvement as an ideal in health care. Nezi Engl \% Mid 1989;320:53-6.

3 Berwick DM, Godfrey AB, Roessner J. Curing health care: nea strategies for quality imprercment. San Francisco, C.A Josser-Bass, 1990

4 James BC. Good cnough? Standards and measurment in continuous quality improzemem. Chicago, IL: Hospita Research and Educational Trust, 1992

5 Laffel G, Blumenthal D. The case for using industrial quality management science in health care organisations. IAMA 1989;262:2869-73.

6 Kritchersky SB, Simmons BP. Continuous quality improvement: concepts and applications for physician care. FAMA 1991;266:1817-23.

7 Berwick DM. Heal thyself or heal thy system: can doctors help to improve medical care? Quality in Hicalth (an 1992;1 (suppl):2-8S

8 Berwick DM. Peer review and quality management: are they compatible? $Q R B$ 1990;16:246-51.

9 Merry MD. Can an external quality review system avoid the inspection model? $Q R B$ 1991;17:315-9.

10 US Congress, General Accounting Office. (quality. assurance: a comprehensice national strategy for hicalth caic is neoded. Washington, DC: US General Accounting Office, 1990.

11 Brooks JHJ, Renz KK, Richardson SL, et al. Systems versus performance problems: a peer review organization's performance problems: a peer
perspective. $Q R B$ 1992;18:172-7.
12 Roberts JS. External review in the brave new world of continuous quality improvement. QRB 1991;17:314

13 Vladeck BC. Quality assurance through external controls. Inquiry 1988;25:100\%7.

14 Ginsburg PB, Hammons GT. Competition and the quality of care: the importance of information. Inquir

15 Milstein A, Nash D, Sands J. Auditing quality of care: an employer based approach. Business and Health 1986 Jul/Aug: $10-12$.

16 Simmons HE, Rhoades MM, Goldberg MA Comprehensive health care reform and managed competition. New Engl f Mcd 1992;327:1525-8.

17 National Committee for Quality Assurance. Opin letter to Bill (Clinton. Washington, I)C: National Committer for Quality Assurance, 1993

18 O'Kane ME. A new approach to accreditation of H.M()s. Foumal of Health Carc Binctits 1991: Sep/Oct: 403.

19 Xational Committee for Quality Assurance. Hialth plan cmpleser data and information sict and users' mamual: acision 2.0. Washington, DC: National Committee for Quality Assurance, 1993 .

20 Cleary PD, McNeil BJ. Patient satisfaction as an indicator of quality care. Inquiny 1988:25:25 36

21 US Congress, Office of Technology Assessment. The yuality of medical care: information for collsumers. Washington, DC: US Office of Technology Assessment, 1988.

22 Donabedian A. Quality assurance in health care consumers' role. Quality in Health Care 1992;1:247-51.

23 Roper WL, Winkenwerder W, Hackbarth GM, Krakauer H Effectiveness in health care: an initiative to evaluate and improve practice. Nez Engl f Med 1988;319:1197202

24 Dubois RW, Rogers WH, Moxley JH, Draper D, Brook RH. Hospital inpatient mortality. Is it a predictor of quality? New Engl 7 Med 1987;317:1674-80.

25 Greenfield SF. Flaws in mortality data: The hazards of ignoring comorbid disease. 7A.1H 1988;260:2253 5 .

26 Dubois RW. Hospital mortality as an indicator of qualits. In: Goldfield N, Nash NB, eds. Providing quality carc: the challonge to clincians. Philadelphia, PA: American College challenge to clinicians. Philade

27 Washington Consumer's Checkbook. Consumer's gruide to hospitals. Washington, $\mathrm{DC}$ : Washington Center for the Study of Services, 1992

28 The Pennsylvania Health Care Cost Containment Council A consumer guide to coronary artery bypass graft surgerv Harrisburg, PA: Pennsiliania Health Care Cost Containment Council, 1992

29 The Pennsylvania Health Care Cost Containment Council. Coromary artery bypass grafting: formal commonts. Harrisburg, PA: Pennsyliania Health Care Cost Containment Council, 1992

30 Luft $H$. The relation between surgical volume and mortality: an exploration of causal factors and alternative models ined Care 1980:18:0+0-59.

31 Luft HS, Hunt SS Evaluating individual hospital yuality through outcome statistics. F A.LA 1986;255:2780

32 Luft HS, Garnick DW, Mark DH, it al. Does quality influence choice of hospital? 7.4.LLA $1900: 263$

33 Lohr KN, ed. Medicar: a strategl for quality assurance. Washington, DC: National Academic Press, 1990

34 Wilensky GR. From the Health Care Financing Administration. FAMA 1991;2810.

35 Jencks SF, Wilensky GR. The health care qualits mprovement initiative: a new approach assurance in Medicare. FAMA 1992;268:90)-3.

36 Lawthers AG, Palmer RH, Edwards J, Fowles J, Garnick DW, Weiner JP. Dereloping and evaluating performance measures for ambulatory care quality: a preliminary report of the DEMPAQ project. Foint (i)mpreliminary report of the DEMPAQ project. 7 oint Com-
mision foumal on Quality Improwement 1993;19:552-65.

37 Lehmann RD. Joint Commission sets agenda for change. QRB 1987; 13:148-50

38 Anonymous. Characteristic of clinical indicators. (ORB 1989;15:330-9.

39 Joint Commission on Accreditation of Healthcare Organisations. Primler on indicater deridopmim and application. Chicago, IL: JCAH(), 1990

to Mechanic D. Cost containment and the quality of medical care: rationing strategies in an era of constrained resources. Milbank Q 1985;63:453 75

41 Brook RH, Davies Avery AA. ()ality uswancic michanisms in the United States from ther to where Santa Monicis. CA: The RAND Corporation, 1975

41 a US Congress. The Health Security Ait. Washington, 1)(: 103 rd US Congress (H R 3600) 1993.

42 The American Medical Peer Reriew Association. Mamaged compctition and the role of quality ocersight. Washington DC: American Peer Review Association, 1993.

43 Michigan Peer Review Organisation and the Center for Health Outcomes and Evaluation. Health care reform: the ned for independen quality assessment. Plymouth, MI: need for independent quality assessment. Plym
Michigan Peer Review Organisation, 1993.

44 Clinton B. Address of the President of the Joint Session of Congress: September 22, 1993. In: White House Domestic Policy Council. Health security: the Prisident: repont to the American people. Washington, I)C: White House Domestic Policy Council, 1993:89-106.

45 Lohr KN. Professional peer review in a "competitive" medical market. Case Wostern Reserve La" Resici" 1986;36:1175-89. 